\title{
Competition and Innovation: An Inverted-U Relationship
}

\section{Citation}

Aghion, Philippe, Nick Bloom, Richard Blundell, Rachel Griffith, and Peter Howitt. 2005.

Competition and innovation: An inverted-U relationship. Quarterly Journal of Economics 120, no. 2: 701-728.

\section{Published Version}

http://dx.doi.org/10.1162/0033553053970214

\section{Permanent link}

http://nrs.harvard.edu/urn-3:HUL.InstRepos:4481507

\section{Terms of Use}

This article was downloaded from Harvard University's DASH repository, and is made available under the terms and conditions applicable to Other Posted Material, as set forth at http:// nrs.harvard.edu/urn-3:HUL.InstRepos:dash.current.terms-of-use\#LAA

\section{Share Your Story}

The Harvard community has made this article openly available.

Please share how this access benefits you. Submit a story.

Accessibility 


\title{
COMPETITION AND INNOVATION: AN INVERTED-U RELATIONSHIP*
}

\author{
Philippe Aghion \\ NiCK BLOOM \\ RICHARD BLUNDELL \\ RACHEL GRIFFITH \\ Peter HowitT
}

\begin{abstract}
This paper investigates the relationship between product market competition and innovation. We find strong evidence of an inverted-U relationship using panel data. We develop a model where competition discourages laggard firms from innovating but encourages neck-and-neck firms to innovate. Together with the effect of competition on the equilibrium industry structure, these generate an inverted-U. Two additional predictions of the model-that the average technological distance between leaders and followers increases with competition, and that the inverted- $U$ is steeper when industries are more neck-and-neck-are both supported by the data.
\end{abstract}

\section{INTRODUCTION}

Economists have long been interested in the relationship between competition and innovation, but economic theory seems to be contradicted by the evidence. Theories of industrial organization typically predict that innovation should decline with competition ${ }^{1}$ while empirical work finds that it increases. ${ }^{2}$ This paper reexamines this relationship using panel data and finds clear nonlinearities in the form of an inverted-U shape, illustrated by Figure I, which plots patents against the Lerner index, with an exponential quadratic overlay. The possibility of an inverted-U relationship between competition and innovation was hinted at by Scherer [1967], who showed a positive relationship between

* The authors would like to thank Daron Acemoglu, William Baumol, Timothy Bresnahan, Jan Boone, Wendy Carlin, Paul David, Janice Eberly, Edward Glaeser, Dennis Ranque, Mark Shankerman, Robert Solow, Manuel Trajtenberg, Alwyn Young, John Van Reenen, two anonymous referees, and participants at seminars including Canadian Institute of Advance Research, Harvard University, and Massachusetts Institute of Technology. Financial support for this project was provided by the Economic and Social Research Council (ESRC) Centre for the Microeconomic Analysis of Public Policy at the Institute for Fiscal Studies, and the ESRC/EPSRC Advanced Institute of Management (AIM) initiative. The data were developed with funding from the Leverhulme Trust.

1. See our discussion in Section III below. However, the replacement effect in Arrow [1962] and the efficiency effects in Gilbert and Newbury [1982] and Reinganum [1983] go in the opposite direction. [1999].

2. See Geroski [1995], Nickell [1996], and Blundell, Griffith, and Van Reenen

๑ 2005 by the President and Fellows of Harvard College and the Massachusetts Institute of Technology.

The Quarterly Journal of Economics, May 2005 
patenting activity and firm size in the cross section, with a diminishing impact at larger sizes when allowing for nonlinearities. To our knowledge, no existing model of product market competition and innovation predicts an inverted-U pattern.

An explanation for these results could be pieced together by combining agency models ${ }^{3}$ with Schumpeterian models; however, this seems unsatisfactory. Instead, we develop an extension of Aghion, Harris, and Vickers $[1997]^{4}$ that can fit the entire curve. In this model both current technological leaders and their followers in any industry can innovate, and innovations by leaders and followers all occur step-by-step. Innovation incentives depend not so much upon postinnovation rents, as in previous endogenous growth models where all innovations are made by outsiders, but upon the difference between postinnovation and preinnovation rents of incumbent firms. In this case, more competition may foster innovation and growth, because it may reduce a firm's preinnovation rents by more than it reduces its postinnovation rents. In other words, competition may increase the incremental profits from innovating, and thereby encourage R\&D investments aimed at "escaping competition." This should be particularly true in sectors where incumbent firms are operating at similar technological levels; in these "neck-and-neck" sectors, preinnovation rents should be especially reduced by product market competition. On the other hand, in sectors where innovations are made by laggard firms with already low initial profits, product market competition will mainly affect postinnovation rents, and therefore the Schumpeterian effect of competition should dominate.

The essence of the inverted-U relationship between competition and innovation is that the fraction of sectors with neck-andneck competitors is itself endogenous, and depends upon equilibrium innovation intensities in the different types of sectors. More specifically, when competition is low, a larger equilibrium fraction of sectors involve neck-and-neck competing incumbents, so that overall the escape-competition effect is more likely to dominate the Schumpeterian effect. On the other hand, when competition is high, the Schumpeterian effect is more likely to dominate, because a larger fraction of sectors in equilibrium have innovation being performed by laggard firms with low initial profits. The inverted-U shape is confirmed by our U. K. panel

3. Hart [1983], Schmidt [1997], Aghion, Dewatripont, and Rey [1999].

4. See also Aghion, Harris, Howitt, and Vickers [2001]. 
data, and it is robust to a number of controls and experiments. ${ }^{5}$ Our model provides additional testable predictions on the relationship between competition and the composition of industries, and more specifically between competition and the average degree of "neck-and-neckness" in the economy, which are also vindicated by the data.

The rest of the paper is structured as follows. Section II displays the empirical evidence on the existence of an inverted-U relationship between competition and innovation. Section III argues that existing models of competition and innovation cannot account for the inverted-U pattern. We develop a theoretical rationale for this relationship, derive some additional empirical predictions, and validate them with data. Finally, Section IV concludes.

\section{The Impact of Competition on Innovation}

The early empirical literature, inspired by Schumpeter [1943], estimated linear cross-sectional relationships and typically found a negative relationship between competition and innovation, confirming the theoretical prejudices of the era. Scherer [1967] developed this research by allowing for additional nonlinearities, and in a cross-sectional analysis of Fortune 500 firms discovered a significant inverted-U shape, with higher competition initially increasing then decreasing the rate of innovation. But research since then has returned to estimating linear specifications; for example, Nickell [1996] and Blundell, Griffith, and Van Reenen [1999] both find a positive linear effect of competition on innovation. In this paper we allow for a nonmonotonic relationship.

\section{II.A. Measuring Innovation}

There is a large literature on measuring innovation intensity, with the most commonly used measures being R\&D expenditure and patenting activity. We use the average number of

5. To deal with the possible endogeneity of competition, we use U. K. data and exploit the major policy reforms undertaken over the 1970s and 1980s, which dramatically changed the nature and extent of competition across industries and over time. The radical policies of the Thatcher administration, the introduction of the European Single Market Program (SMP), and the reforms imposed by the Monopolies and Mergers Commission together provide a number of policy changes that vary across time and industries and allow us to identify the causal impact of competition on innovation. 
patents taken out by firms in an industry, and to reflect the heterogeneous value of patents, we weight each patent by the number of times it has been cited by another patent. These data are generated by matching the NBER patents database ${ }^{6}$ to accounting data on firms listed on the London Stock Exchange (from Datastream). Our sample includes all firms with names beginning "A" to "L" plus all large R\&D firms. After removing firms involved in large mergers or acquisitions and those with missing data, we have an unbalanced panel of 311 firms spanning seventeen two-digit SIC codes over the period 1973-1994. We also have information on citations to and from each patent, which enables us to construct a count of citation-weighted patents. We take the average value of citation-weighted patents of firms within each industry (SIC code) in each year. We do not observe a sufficient number of firms in all industries in all years, so our resulting industry level panel is also unbalanced with 354 industry-year observations. Some descriptive statistics are provided in Appendix 2.

\section{II.B. Measuring Competition}

Our main indicator of product market competition is the Lerner Index, or price cost margin, following Nickell [1996]. This measure has several advantages over indicators such as market share or the Herfindahl concentration index. These other measures rely more directly on precise definitions of geographic and product markets, which is particularly difficult in our application, as many U. K. firms operate in international markets, so that market concentration measures based only on U. K. data may be extremely misleading.

The price cost margin we use is measured by operating profits net of depreciation, provisions and an estimated financial cost of capital ${ }^{7}$ divided by sales,

$$
l i_{i t}=\frac{\text { operating profit }- \text { financial cost }}{\text { sales }} .
$$

6. See Hall, Jaffe, and Trajtenberg [2000]. The NBER database contains the patents taken out in the U. S. patent office, which is where innovations are effectively patented internationally, dated by the time of application.

7. The cost of capital is assumed to be 0.085 for all firms and time periods and the capital stock is measured using the perpetual inventory method. The inverted-U shape is robust to excluding this financial cost from the Lerner measure, principally because it is relatively small and constant over time. 
Our competition measure is the average of this across firms within the industry,

$$
c_{j t}=1-\frac{1}{N_{j t}} \sum_{i \in j} l i_{i t},
$$

where $i$ indexes firms, $j$ indexes industry, $t$ indexes time, and $N_{j t}$ is the number of firms in industry $j$ in year $t$. A value of 1 indicates perfect competition (price equals marginal cost) while values below 1 indicate some degree of market power. In computing this index, we use the entire sample of Stock Market Listed firms in each industry, not only those in the patenting subsample.

\section{II.C. A Nonlinear Relationship}

We use flexible nonlinear estimators to investigate the basic shape of the relationship between competition and innovation. Denoting $n$ as the hazard rate and $c$ as the measure of competition, we start by defining the competition innovation relationship as

$$
n=e^{g(c)} \text {, where } g(\cdot) \text { is some unknown function. }
$$

Suppose that the patent process has a Poisson distribution with hazard rate (2), then the expected number of patents satisfies

$$
E[p \mid c]=e^{g(c)} .
$$

Parametric models that study count data processes typically base their specification on the Poisson model with a parametric (linear) form for $g(c)$, but they relax the strong assumptions on higher moments. ${ }^{8}$ We follow this approach in our empirical analysis, basing our estimator on the first moment (3). We adopt a flexible specification for $g(c)$, because we are particularly interested in allowing the data to determine the shape of the relationship between innovation and product market competition.

It is very likely that different industries will have observed levels of patenting activity that have no direct causal relationship with product market competition, but reflect other institutional features of the industry. Consequently, industry fixed effects are essential to remove any spurious correlation or "endogeneity" of this type. Time effects are also included to remove common macroeconomic shocks. Conditional on industry and time effects, in-

8. See Hausman, Hall, and Griliches [1984], for example. 


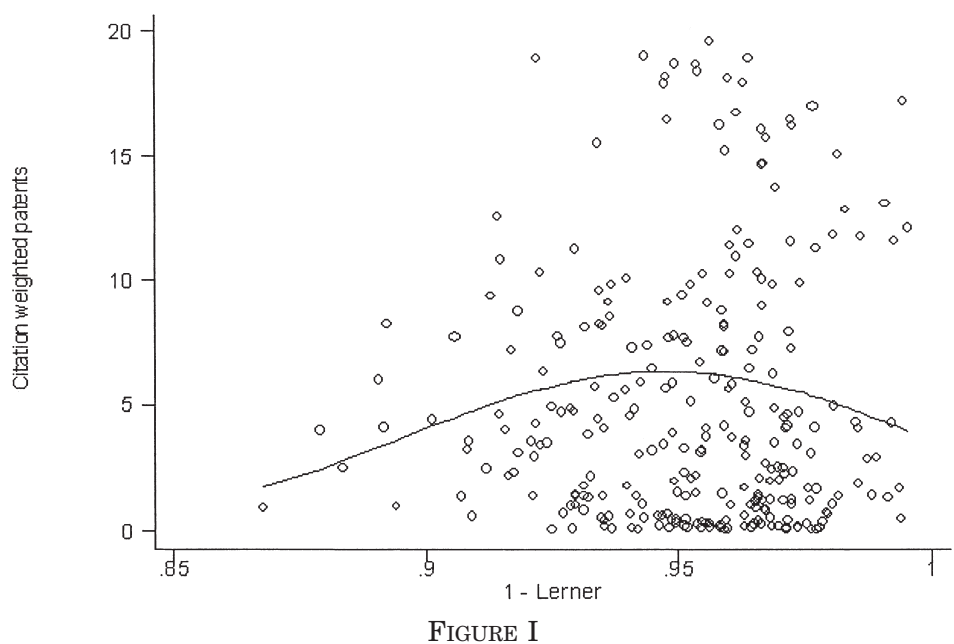

Scatter Plot of Innovation on Competition

The figure plots a measure of competition on the $x$-axis against citationweighted patents on the $y$-axis. Each point represents an industry-year. The scatter shows all data points that lie in between the tenth and ninetieth deciles in the citation-weighted patents distribution. The exponential quadratic curve that is overlaid is reported in column (2) of Table I.

dustry patent behavior is related to industry competition according to

$$
E\left[p_{j t} \mid c_{j t}, x_{j t}\right]=e^{\left\{g\left(c_{j t}\right)+x_{j t}^{\prime} \beta\right\}},
$$

where $x_{j t}$ represents a complete set of time and industry dummy variables. We use moment condition (4) to define a semiparametric moment estimator and approximate $g(c)$ with a spline, following $\mathrm{Ai}$ and Chen [2003].

In Figure I we show the scatter of data points in between the tenth and ninetieth deciles of the citation-weighted patent distribution, and overlay a fitted exponential quadratic curve. The same exponential quadratic curve is plotted together with a spline approximation in Figure II. It can be seen that the exponential quadratic specification provides a very reasonable approximation to the nonparametric spline, and that they both show a clear inverted-U shape. The estimated coefficients for the exponential quadratic model are presented in Table I. The first column shows that both the linear and quadratic terms are individually and jointly significant. In the second column we reestimate including industry effects, which is our preferred specification, 


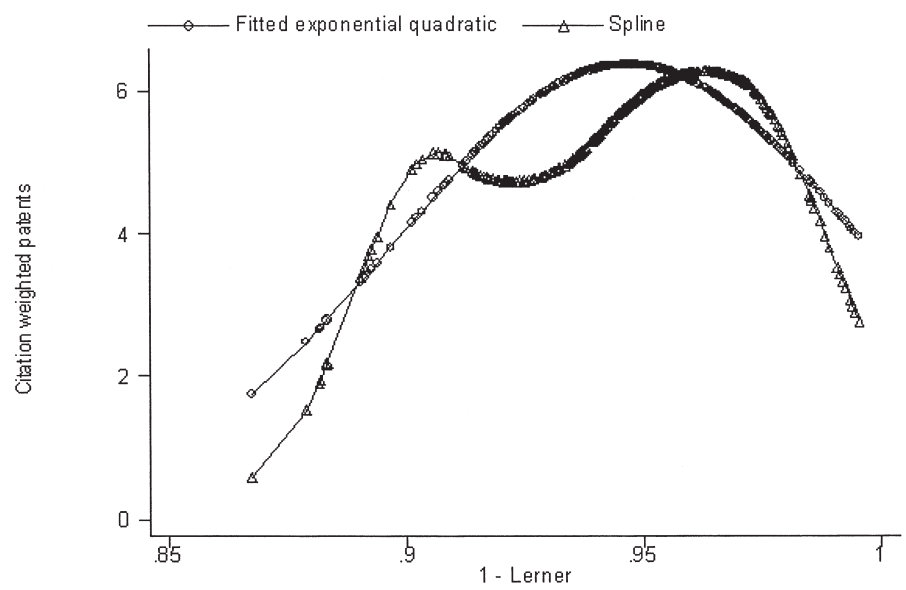

FiguRE II

Innovation and Competition: Exponential Quadratic and the Semiparametric Specifications with Year and Industry Effects

The figure plots a measure of competition on the $x$-axis against citationweighted patents on the $y$-axis. Each point represents an industry-year. The circles show the exponential quadratic curve that is reported in column (2) of Table I. The triangles show a nonparametric spline.

and which removes the bias that results from correlation between permanent levels of innovative activity and product market competition, and again find a significant inverted-U shape.

The underlying distribution of the data is shown by the intensity of the points on the estimated curves. These indicate that the peak of the inverted U lies near the median of the distribution (the median is 0.95 ) so that industries are well spread across the U-shape. We can also see that a linear relationship would yield a positive slope, confirming the results presented in Nickell [1996]. Before moving to the results using the policy instruments, we consider three robustness checks. The first uses five-year averages to estimate this relationship in view of the potential lags in the relationship between competition and innovation. As shown in the third column of Table I, this also displays a clear inverted-U shape. ${ }^{9}$ The second robustness check, not shown, uses R\&D expenditure as an alternative innovation measure. Again, we find an inverted-U shape, although due to a

9. The data span a 22-year period (1973 to 1994). Therefore, the first period was set at seven years with the remainder at five years each. 
TABLE I

Exponential QuAdratic: Basic SPECIFICATION

\begin{tabular}{|c|c|c|c|c|}
\hline $\begin{array}{l}\text { Dependent variable: citation- } \\
\text { weighted patents }\end{array}$ & Annual & Annual & $\begin{array}{c}(3) \\
5 \text {-year } \\
\text { averages }\end{array}$ & Annual \\
\hline Competition $_{j t}$ & $\begin{array}{l}152.80 \\
(55.74)\end{array}$ & $\begin{array}{l}387.46 \\
(67.74)\end{array}$ & $\begin{array}{c}819.44 \\
(265.63)\end{array}$ & $\begin{array}{l}385.13 \\
(67.56)\end{array}$ \\
\hline Competition squared $_{j t}$ & $\begin{array}{l}-80.99 \\
(29.61)\end{array}$ & $\begin{array}{l}-204.55 \\
(36.17)\end{array}$ & $\begin{array}{l}-434.43 \\
(141.43)\end{array}$ & $\begin{array}{c}-204.83 \\
(36.06)\end{array}$ \\
\hline $\begin{array}{l}\text { Significance of: Competition }_{j t} \text {, } \\
\text { Competition squared }{ }_{i t}\end{array}$ & $\begin{array}{c}7.60 \\
(0.02)\end{array}$ & $\begin{array}{l}38.34 \\
(0.00)\end{array}$ & $\begin{array}{c}9.97 \\
(0.01)\end{array}$ & $\begin{array}{l}32.59 \\
(0.00)\end{array}$ \\
\hline $\begin{array}{l}\text { Significance of policy instruments } \\
\text { in reduced form }\end{array}$ & & & & $\begin{array}{c}10.11 \\
(0.002)\end{array}$ \\
\hline $\begin{array}{l}\text { Significance of other instruments } \\
\text { in reduced form }\end{array}$ & & & & $\begin{array}{c}5.00 \\
(0.000)\end{array}$ \\
\hline Control functions in regression & & & & $\begin{array}{c}4.38 \\
(4.04)\end{array}$ \\
\hline$R^{2}$ of reduced form & & & & 0.801 \\
\hline Year effects & Yes & Yes & Yes & Yes \\
\hline Industry effects & & Yes & Yes & Yes \\
\hline Observations & 354 & 354 & 67 & 354 \\
\hline
\end{tabular}

Competition $_{j t}$ is measured by (1-Lerner index) in the industry-year. All columns are estimated using an unbalanced panel of seventeen industries over the period 1973 to 1994. Estimates are from a Poisson regression. Numbers in brackets are standard errors. The standard errors in column (4) have not been corrected for the inclusion of the control function. Significance tests show likelihood ratio test-statistics and $P$-value from the $F$-test of joint significance. The fourth column includes a control function. The excluded variables are policy instruments specified in Table II, imports over value-added in the same industry-year, TFP in the same industry-year, output minus variable costs over output in the same industry-year and estimates of markups from industry-country regression [Martins et al. 1996] interacted with time trend, all for the United States and France.

substantially smaller sample ${ }^{10}$ the coefficients are not statistically significant. Finally, we fit the relationship for each of the top four innovating industries in our sample, and in each case there is part or all of an inverted-U shape (see the earlier working paper version of this paper [Aghion et al. 2004]).

\section{II.D. Using Policy Instruments}

The major obstacle to empirical research in this area is that competition and innovation are mutually endogenous. Without addressing this, any results we find are likely to be biased toward

10. In the United Kingdom R\&D was not a mandatory reporting item prior to 1990 , so it is not available for the majority of firms prior to this date. This is one of the reasons we use citation-weighted patents as our main innovation indicator. 
TABLE II

Policy InSTRUMents

\begin{tabular}{lcc}
\hline \hline \multicolumn{1}{c}{ Industry } & Year(s) & Policy \\
\hline All, but differential impacts & 1988 & Single Market Program \\
Brewing & 1986 & MMC action \\
Cars & $1984,1987,1988$ & MMC action, Privatization \\
Car parts & 1982,1987 & MMC action, Privatization \\
Periodicals & 1987 & MMC action \\
Razors and blades & 1990 & MMC action \\
Ordnance & 1987 & Privatization \\
Steel & 1987 & Privatization \\
Telecoms & $1981,1984,1989$ & MMC action, Privatization \\
Textiles & 1989 & MMC action \\
\hline \hline
\end{tabular}

finding a more negative relationship between competition and innovation if higher levels of innovation act, for example, to reduce competition. ${ }^{11} \mathrm{We}$ address this problem by using a set of policy instruments that provide exogenous variation in the degree of industrywide competition. Since we are including industry and time effects, this approach identifies the competition effect through the differential timing of the introduction of policy changes across industries. The three sets of policy instrument used are the Thatcher era privatizations, the EU Single Market Programme, ${ }^{12}$ and the Monopoly and Merger Commission investigations that resulted in structural or behavioral remedies being imposed on the industry. Table II lists the policy instruments that are used, the industries that are affected, and the year(s) in which the policy changes occurred.

We use these policy variables to instrument the changes in competition. These policy changes were driven by a combination of political orthodoxy, desires for European integration, and regulatory responses to anticompetitive behavior, with little obvious link to industry-level innovation performance. We specify a reduced-form model for the competition measure:

11. See, for example, the endogenous barrier to entry story in Sutton [1998].

12. See the earlier working paper version for full details of all the policy instruments [Aghion et al. 2004]. The Single Market Program differentially increased trade liberalization across U. K. industries in 1988. All tariff and nontariff barriers were phased out, with the increase in competition depending on the extent of pre-SMP tariff and nontariff barriers. The European Commission's Cechinni report ranked all three-digit SIC industries into low, medium, and high impact, and we use this ranking for our policy instrument identification. 


$$
c_{j t}=\pi\left(z_{j t}\right)+x_{j t}^{\prime} \gamma+v_{j t},
$$

which assumes that $E\left[v_{j t} \mid z_{j t}, x_{j t}\right]=0$, where $z_{j t}$ denote the policy instruments. The idea is then to use functions of the $v_{j t}$ as controls in an extended version of the moment condition to strip out any element of $c_{j t}$ which is endogenous with the error term. The control function assumption can be expressed as

$$
E\left[e^{u_{j t} \mid} c_{j t}, x_{j t}, v_{j t}\right]=1 \text {, }
$$

so that controlling for $v_{j t}$ in the conditional moment condition is sufficient to retrieve the conditional moment assumption. ${ }^{13}$

The fourth column in Table I shows the estimates for our exponential quadratic specification that control for endogeneity using our set of instruments. The coefficient estimates are similar to the second column. In the bottom part of the table, we present some diagnostic statistics. They show that the instruments are significant in the reduced form, that the policy instruments in particular are significant, and that they have explanatory power. The relationship between innovation and product market competition for the standard quadratic and also for the instrumented quadratic display a similar inverted-U relationship.

\section{EXPLAINING THE INVERTED U}

\section{III.A. Main Existing Theories of Competition and Innovation}

In this subsection we briefly summarize what existing theories have to say about the relationship between competition and innovation or competition and productivity growth. As it turns out, none of them can account for the inverted-U pattern described in the previous section.

The leading IO models of product differentiation and monopolistic competition, namely Salop [1977]) and Dixit and Stiglitz [1977], deliver the prediction that more intense product market competition ${ }^{14}$ reduces postentry rents, and therefore reduces the equilibrium number of entrants. Thus, these models can only account for the decreasing part of the inverted-U curve: increased

13. To recover the parameters of interest, we integrate over the empirical distribution of $v$ and recover the "average structural function" (see Blundell and Powell [2003]).

14. Increased product market competition is modeled as a reduction in unit transport cost in Salop [1977] or as an increase in the substitutability between differentiated products in Dixit and Stiglitz [1977]. 
product market competition discourages innovation by reducing postentry rents. This prediction is shared by most existing models of endogenous growth (e.g., Romer [1990], Aghion and Howitt [1992], and Grossman and Helpman [1991]), where an increase in product market competition, or in the rate of imitation, has a negative effect on productivity growth by reducing the monopoly rents that reward new innovation. ${ }^{15}$

In all the above-mentioned papers, firms are simply profitmaximizing individuals. Instead, Hart [1983] considers the case of firms run by so-called "satisficing" managers who do not value profits per se, but yet draw private benefits from maintaining the firm afloat and thereby keeping their job. Then, increased competition may induce otherwise reluctant managers to put more effort into reducing costs in order to avoid bankruptcy. ${ }^{16}$ However, this does not generate an inverted-U relationship between competition and managerial incentives: either most firms have managers who are a sufficiently residual claimant over the firm's monetary revenue, in which case we again obtain a negative correlation between competition and innovation, or they are run by satisficing managers, in which case competition is unambiguously good for innovation.

\section{III.B. A Theoretical Framework}

There is a unit mass of identical consumers, each supplying a unit of labor inelastically, with a constant rate of intertemporal discount $r$ and a logarithmic instantaneous utility function $u\left(y_{t}\right)=\ln y_{t}$. The consumption good $y$ is produced at each date $t$ using input services from a continuum of intermediate sectors, according to the production function,

$$
\ln y_{t}=\int_{0}^{1} \ln x_{j t} d j,
$$

in which each $x_{j}$ is an aggregate of two intermediate goods produced by duopolists in sector $j$, defined by the subutility function,

15. In these models the reason why competition policy is unambiguously detrimental to growth is the same as the reason why patent protection is unambiguously good for growth: patent protection raises monopoly rents from innovation whereas increased product market competition destroys these rents.

16. This positive effect of competition disappears if managers value monetary payoffs sufficiently, as shown by Scharfstein [1988] and more recently by Schmidt [1997]. 


$$
x_{j}=x_{A j}+x_{B j} .
$$

The logarithmic structure of (7) implies that in equilibrium individuals spend the same amount on each basket $x_{j}$. We normalize this common amount to unity by using current expenditure as the numeraire for the prices $p_{A j}$ and $p_{B j}$ at each date. Thus, the representative household chooses each $x_{A j}$ and $x_{B j}$ to maximize $x_{A j}+x_{B j}$ subject to the budget constraint: $p_{A j} x_{A j}+$ $p_{B j} x_{B j}=1$.

Each firm produces using labor as the only input, according to a constant-returns production function, and takes the wage rate as given. Thus, the unit costs of production $c_{A}$ and $c_{B}$ of the two firms in an industry are independent of the quantities produced. Now, let $k$ denote the technology level of duopoly firm $i$ in some industry $j$; that is, one unit of labor currently employed by firm $i$ generates an output flow equal to

$$
A_{i}=\gamma^{k_{i}}, \quad i=A, B,
$$

where $\gamma>1$ is a parameter that measures the size of a leadingedge innovation. Equivalently, it takes $\gamma^{-k_{i}}$ units of labor for firm $i$ to produce one unit of output. The state of an industry is then fully characterized by a pair of integers $(l, m)$, where $l$ is the leader's technology and $m$ is the technology gap of the leader over the follower. We define $\pi_{m}$ (respectively, $\pi_{-m}$ ) to be the equilibrium profit flow of a firm $m$ steps ahead of (respectively, behind) its rival. ${ }^{17}$

For expositional simplicity, we assume that knowledge spillovers between leader and follower in any intermediate industry are such that the maximum sustainable gap is $m=1$. That is, if a firm already one step ahead innovates, the lagging firm will automatically learn to copy the leader's previous technology and thereby remain only one step behind. Thus, at any point in time, there will be two kinds of intermediate sectors in the economy: (i) leveled or neck-and-neck sectors where both firms are at technological par with one another, so that $m=0$; (ii) unleveled sectors, where one firm (the leader) lies one step ahead of its competitor (the laggard or follower) in the same industry, so that $m=1 .^{18}$

17. The above logarithmic technology along with the cost structure $c(x)=x$. $\gamma^{-k}$ implies that the profit in the industry depends only on the gap $m$ between the two firms, and not on absolute levels of technology.

18. Aghion et al. [2001] analyze the more general case where $m$ is unbounded. However, unlike in this section, that paper provides no closed-form solution for the equilibrium R\&D levels and the steady-state industry structure, 
By spending the R\&D cost $\psi(n)=n^{2} / 2$ in units of labor, a leader (or frontier) firm moves one technological step ahead, with a Poisson hazard rate of $n$. We call $n$ the "innovation rate" or "R\&D intensity" of the firm. We assume that a follower firm can move one step ahead with hazard rate $h$, even if it spends nothing on $\mathrm{R} \& \mathrm{D}$, by copying the leader's technology. Thus $n^{2} / 2$ is the R\&D cost of a follower firm moving ahead with a hazard rate $n+$ $h$. Let $n_{0}$ denote the R\&D intensity of each firm in a neck-andneck industry; and let $n_{-1}$ denote the R\&D intensity of a follower firm in an unleveled industry; if $n_{1}$ denotes the R\&D intensity of the leader in an unleveled industry, note that $n_{1}=0$, since our assumption of automatic catch-up means that a leader cannot gain any further advantage by innovating.

We model the degree of product market competition inversely by the degree to which the two firms in a neck-and-neck industry are able to collude. They do not collude when the industry is unlevel. Thus, the laggard in an unlevel industry makes zero profit, while the leader makes a profit equal to the difference between its revenue, which we have normalized to unity, and its cost, which is $\gamma^{-1}$ times its revenue, given that its price is $\gamma$ times its unit cost:

$$
\pi_{-1}=0 \quad \text { and } \quad \pi_{1}=1-\gamma^{-1} .
$$

Each firm in a level industry earns a profit of 0 if the firms are unable to collude, since they are in Bertrand competition with identical products and identical unit costs, and $\pi_{1} / 2$ if there is maximum collusion. More generally, we assume that

$$
\pi_{0}=\varepsilon \pi_{1}, \quad 0 \leq \varepsilon \leq 1 / 2,
$$

and we parameterize product market competition by $\Delta=1-\varepsilon$, that is, one minus the fraction of a leader's profits that the level firm can attain through collusion. Note that $\Delta$ is also the incremental profit of an innovator in a neck-and-neck industry, normalized by the leader's profit.

We next analyze how the equilibrium research intensities $n_{0}$ and $n_{-1}$, and consequently the aggregate innovation rate, vary with our measure of competition.

and therefore cannot formally establish qualitative results such as the existence of an inverted-U relationship between competition and innovation or characterize the relationship between competition and the distribution of technological gaps. 


\section{III.C. The Schumpeterian and "Escape-Competition" Effects}

We assume that the equilibrium innovation rates $n_{0}$ and $n_{-1}$ are determined by the necessary conditions for a symmetric Markov-stationary equilibrium in which each firm seeks to maximize expected discounted profits, with a discount rate $r=0 .{ }^{19} \mathrm{In}$ Appendix 1 we establish

Proposition 1 . The equilibrium research intensity by each neckand-neck firm is

$$
n_{0}=\sqrt{h^{2}+2 \Delta \pi_{1}}-h,
$$

which increases with higher product market competition $\Delta$, whereas the equilibrium research intensity of a laggard firm is

$$
n_{-1}=\sqrt{h^{2}+n_{0}^{2}+2 \pi_{1}}-h-n_{0},
$$

which decreases with higher product market competition $\Delta$.

The latter effect (on $n_{-1}$ ) is the basic Schumpeterian effect that results from reducing the rents that can be captured by a follower who succeeds in catching up with its rival by innovating. The former effect (on $n_{0}$ ) we refer to as an "escape-competition effect," namely that more competition induces neck-and-neck firms to innovate in order to escape competition, since the incremental value of getting ahead is increased with higher PMC. On average, an increase in product market competition will thus have an ambiguous effect on growth. It induces faster productivity growth in currently neck-and-neck sectors and slower growth in currently unleveled sectors. The overall effect on growth will thus depend on the (steady-state) fraction of leveled versus unleveled sectors. But this steady-state fraction is itself endogenous, since it depends upon equilibrium R\&D intensities in both types of sectors. We proceed to show under which condition this overall effect is an inverted $U$, and at the same time derive additional predictions for further empirical testing.

Let $\mu_{1}$ (respectively, $\mu_{0}$ ) denote the steady-state probability of being an unleveled (respectively, neck-and-neck) industry. During any unit time interval, the steady-state probability that a sector moves from being unleveled to leveled is $\mu_{1}\left(n_{-1}+h\right)$, and

19. We have established by numerical simulation that all of our results hold with $r>0$. 
the probability that it moves in the opposite direction is $2 \mu_{0} n_{0}$. In steady state, these two probabilities must be equal

$$
\mu_{1}\left(n_{-1}+h\right)=2 \mu_{0} n_{0} .
$$

This, together with the fact that $\mu_{1}+\mu_{0}=1$, implies that the aggregate flow of innovations is

(10) $I=2 \mu_{0} n_{0}+\mu_{1}\left(n_{-1}+h\right)=2 \mu_{1}\left(n_{-1}+h\right)=\frac{4 n_{0}\left(n_{-1}+h\right)}{2 n_{0}+n_{-1}+h}$.

We now analyze how this flow varies with product market competition and establish the possibility of an inverted-U pattern. Since by Proposition $1, n_{0}$ is an increasing function of $\Delta$, we can use $n_{0}$ as our proximate measure of product market competition, which in turn will prove convenient when deriving our main predictions below. Note that $n_{0}$ takes values on the interval $\left[\underline{x}=\sqrt{h^{2}+\pi_{1}}-h, \bar{x}=\sqrt{h^{2}+2 \pi_{1}}-h\right]$, with $x=\underline{x}$ corresponding to maximum collusion $\left(\pi_{0}=\pi_{1} / 2\right)$ and $x=\bar{x}$ corresponding to maximum competition $\left(\pi_{0}=0\right)$. We have

Proposition 2. Whenever the value $\tilde{x}=\sqrt{\left[h^{2}+2 \pi_{1}\right] / 3}$ is interior to the interval $[\underline{x}, \bar{x}]$, the aggregate innovation rate $v\left(n_{0}\right)$ follows an inverted-U pattern: it increases with competition $n_{0}$ for all $n_{0} \in[\underline{x}, \tilde{x})$ and decreases for all $n_{0} \in(\tilde{x}, \bar{x}]$. If $\tilde{x}>$ $\bar{x}$, then the aggregate innovation rate increases with $n_{0}$ for all $n_{0} \in[\underline{x}, \bar{x}]$ so that the escape-competition effect always dominates. If $\tilde{x}<\underline{x}$, then it decreases with $n_{0}$ for all $n_{0} \in$ $[\underline{x}, \bar{x}]$ so that the Schumpeterian effect always dominates. Moreover, each of these cases arises for a nonempty subset of parameter values.

Proof. See Appendix 1.

The inverted-U shape can be explained as follows. When there is not much product market competition, there is hardly any incentive for neck-and-neck firms to innovate, and therefore the overall innovation rate will be highest when the sector is unleveled. Thus, the industry will be quick to leave the unleveled state (which it does as soon as the laggard innovates) and slow to leave the leveled state (which will not happen until one of the neck-and-neck firms innovates). As a result, the industry will spend most of the time in the leveled state, where the escapecompetition effect dominates $\left(n_{0}\right.$ is decreasing in $\left.\pi_{0}\right)$. In other words, if the degree of competition is very low to begin with, an 
increase in competition should result in a faster average innovation rate.

On the other hand, when competition is initially very high, there is relatively little incentive for the laggard in an unleveled state to innovate. Thus, the industry will be relatively slow to leave the unleveled state. Meanwhile, the large incremental profit $\pi_{1}-\pi_{0}$ gives firms in the leveled state a relatively large incentive to innovate, so that the industry will be relatively quick to leave the leveled state. As a result, the industry will spend most of the time in the unleveled state where the Schumpeterian effect is at work on the laggard, while the leader never innovates. In other words, if the degree of competition is very high to begin with, an increase in competition should result in a slower average innovation rate. ${ }^{20}$

Note that, according to this model, the empirical measure $c$ of competition, that we used in the previous section, has an expected value of

$$
c=1-\mu_{1} \frac{\pi_{1}}{2}-2\left(1-\mu_{1}\right)(1-\Delta) \pi_{1} .
$$

That is, in accordance with equation (1) above, the industry average Lerner index in an uneven industry is $\pi_{1} / 2$, since the laggard has a Lerner of zero, whereas the industry average Lerner index in a leveled industry is the Lerner index of each firm, equal to its profits divided by its revenue: $\pi_{0} /(1 / 2)=2(1-\Delta) \pi_{1}$. We show in Appendix 1 that in our model

Proposition 3. The empirical measure $c$ defined by (11) is a monotonically increasing function of the theoretical measure $\Delta$ used in the other propositions.

\section{III.D. Additional Predictions on Technological Spread and Competition}

In addition to providing a rationale for the inverted-U pattern uncovered in the previous section, the model delivers two additional predictions, which are summarized in the following two propositions and which we prove in Appendix 1.

20. Thus, the reason why the escape-competition effect dominates when competition is low, whereas the Schumpeterian effect on laggards dominates when competition is intense is the "composition effect" of competition on the steady-state distribution of technology gaps across sectors. 
Proposition 4. The expected technological gap in an industry increases with product market competition.

The intuition is simple: we know that the higher the degree of product market competition, the higher the research intensity in neck-and-neck sectors, and the lower the research intensity in unleveled sectors. This, in turn, implies that any sector will spend a higher fraction of its time being unleveled, so that on average over time the technological gap between firms in that sector will be higher. By the law of large numbers the same will be true for the economy as a whole at any point in time.

The next proposition is equally intuitive: it states the existence of a positive interaction between the escape-competition effect and the average distance of the industry to its frontier, in the sense that in industries where firms are closer to their technological frontier over time, the escape-competition effect tends to be stronger (that is, the increasing part of the inverted $U$ tends to be steeper). More precisely, suppose that there are industries with large spillover parameter $h$ and industries with small $h$. Those with large $h$ will tend to be more neck-and-neck on average over time. ${ }^{21}$ Now, we can compare the magnitude of the escapecompetition effect across industries with different values of $h$ and establish that

Proposition 5. The peak of the inverted $U$ is larger, and occurs at a higher degree of competition, in more neck-and-neck industries. More formally, let $\tilde{\Delta}$ be the incremental profit at which $x=\tilde{x}=\sqrt{\left[h^{2}+2 \pi_{1}\right] / 3}$; then both $\tilde{\Delta}$ and $\nu(\tilde{x})$ are increasing in $h$.

Proof. See Appendix 1.

\section{III.E. Testing the Technological Spread Predictions}

To empirically assess the predictions on the technological spread and competition relationship, we first need a measure of the size of the technology gap between firms within an industry. We capture this by the proportional distance a firm is from the technological frontier, as measured by total factor productivity. More formally, we let

21. This is formally established in Appendix 1, in the remark following the proof of Proposition 4. 


$$
m_{i t}=\left(T F P_{F t}-T F P_{i t}\right) / T F P_{F t},
$$

where $F$ denotes the frontier firm (with the highest TFP) and $i$ denotes nonfrontier firms. So, at the firm level, $m_{i t}>0$, and $m_{F t}=0$. We use an industry level measure $m_{j t}$ that is the average across firms in the industry. A lower value of $m_{j t}$ indicates that firms in industry $j$ are technologically closer to the frontier (and therefore more like the neck-and-neck firms in our theoretical section), while a high value of $m_{j t}$ indicates a large technological gap with the frontier (so that firms in those industries are more like laggard firms in an unleveled industry).

The first key prediction on the technological spread is that, in equilibrium, the average technology gap between leaders and followers should be an increasing function of the overall level of industrywide competition (so that average neck-and-neckness should be a decreasing function of competition). This is tested and confirmed in Table III, which reports the results from regressing the industry average technology gap on the Lerner index with a full set of year dummies (first column) and a full set of year and industry dummies (second column). In both cases there is a significantly positive coefficient, suggesting that industries with greater levels of competition have a higher average spread in technology within the industry and a lower degree of technology neck-and-neckness.

This result is perhaps surprising because the static intuition is that higher competition should reduce the spread of TFP by increasing the exit rate of low TFP firms, truncating the lower tail of the distribution. But empirically we find this static effect of competition appears to be dominated by a more powerful dynamic effect to increase the rate of innovation. As firms innovate to try to escape competition, they increase the spread of TFP within the industry, dominating any potential selective exit effect.

The second theoretical prediction is that the inverted-Ushaped relationship between competition and growth should be steeper in more neck-and-neck industries. To assess this prediction, we consider a subsample of our data-industries with below median technological gap-which are the more neckand-neck industries. Figure III shows our baseline fitted exponential quadratic curve, as well as an exponential quadratic curve fitted to the subsample of high neck-and-neck industries. 
TABLE III

Technology Gap and Exponential Quadratic with Neck-AND-Neck Split

\begin{tabular}{|c|c|c|c|c|}
\hline Dependent variable: & $\begin{array}{c}(1) \\
\text { Technology } \\
\text { gap }\end{array}$ & $\begin{array}{c}(2) \\
\text { Technology } \\
\text { gap }\end{array}$ & $\begin{array}{c}(3) \\
\text { Citation- } \\
\text { weighted } \\
\text { patents }\end{array}$ & $\begin{array}{c}(4) \\
\text { Citation- } \\
\text { weighted } \\
\text { patents }\end{array}$ \\
\hline Estimation procedure & $\begin{array}{l}\text { Linear } \\
\text { regression }\end{array}$ & $\begin{array}{l}\text { Linear } \\
\text { regression }\end{array}$ & Poisson & Poisson \\
\hline Competition $_{j t}$ & $\begin{array}{c}2.858 \\
(0.400)\end{array}$ & $\begin{array}{c}0.942 \\
(0.419)\end{array}$ & $\begin{array}{l}183.81 \\
(58.99)\end{array}$ & $\begin{array}{l}424.46 \\
(69.5)\end{array}$ \\
\hline Competition squared $_{j t}$ & & & $\begin{array}{l}-96.35 \\
(31.01)\end{array}$ & $\begin{array}{l}-222.9 \\
(36.9)\end{array}$ \\
\hline $\begin{array}{l}\text { Competition }_{j t} * \text { Technology } \\
\operatorname{gap}_{j t}\end{array}$ & & & $\begin{array}{l}1.43 \\
(2.48)\end{array}$ & $\begin{array}{l}3.82 \\
(2.66)\end{array}$ \\
\hline $\begin{array}{l}\text { Competition squared } \\
{\text { Technology } \text { gap }_{j t}}\end{array}$ & & & $\begin{array}{l}-1.30 \\
(2.59)\end{array}$ & $\begin{array}{l}-3.84 \\
(2.78)\end{array}$ \\
\hline \multicolumn{5}{|l|}{ Significance of: } \\
\hline $\begin{array}{l}\text { Competition }_{j t} \text {, } \\
\text { Competition squared } \\
j t\end{array}$ & & & $\begin{array}{l}16.59 \\
(0.00)\end{array}$ & $\begin{array}{l}39.21 \\
(0.00)\end{array}$ \\
\hline \multicolumn{5}{|l|}{ Significance of: } \\
\hline $\begin{array}{l}\text { Competition }_{j t} * \text { Technology } \\
\text { gap }_{j t},\end{array}$ & & & 9.74 & 7.93 \\
\hline $\begin{array}{l}\text { Competition squared } \\
\text { Technology }_{\text {gap }} *\end{array}$ & & & $(0.01)$ & $(0.02)$ \\
\hline Year effects & Yes & Yes & Yes & Yes \\
\hline Industry effects & & Yes & & Yes \\
\hline
\end{tabular}

Competition $_{j t}$ is measured by (1-Lerner index) in the industry-year. Technology gap $j t$ is measured by the average distance to the TFP frontier firm across all firms in the industry-year, so it is an inverse measure of neck-and-neckness. All columns estimated using an unbalanced panel of 354 yearly observations on seventeen industries over the period 1973 to 1994. Significance tests show likelihood ratio test-statistics and $P$-value from the $F$-test of joint significance. Numbers in brackets are standard errors. The standard errors in columns 3 and 4 have not been corrected for the inclusion of the control function.

Two features stand out clearly. First, more neck-and-neck industries show a higher level of innovation activity for any level of product market competition. Second, the inverted-U curve is steeper for the more neck-and-neck industries, which accords well with our theoretical predictions. These differences are statistically significant, as shown in columns 3 and 4 of Table II, which reports the quadratic coefficients for the whole sample and the high neck-and-neck industry subsample including a full set of year dummies (third column) and a full set of year and industry dummies (fourth column). The interaction terms are jointly significant in both cases. 


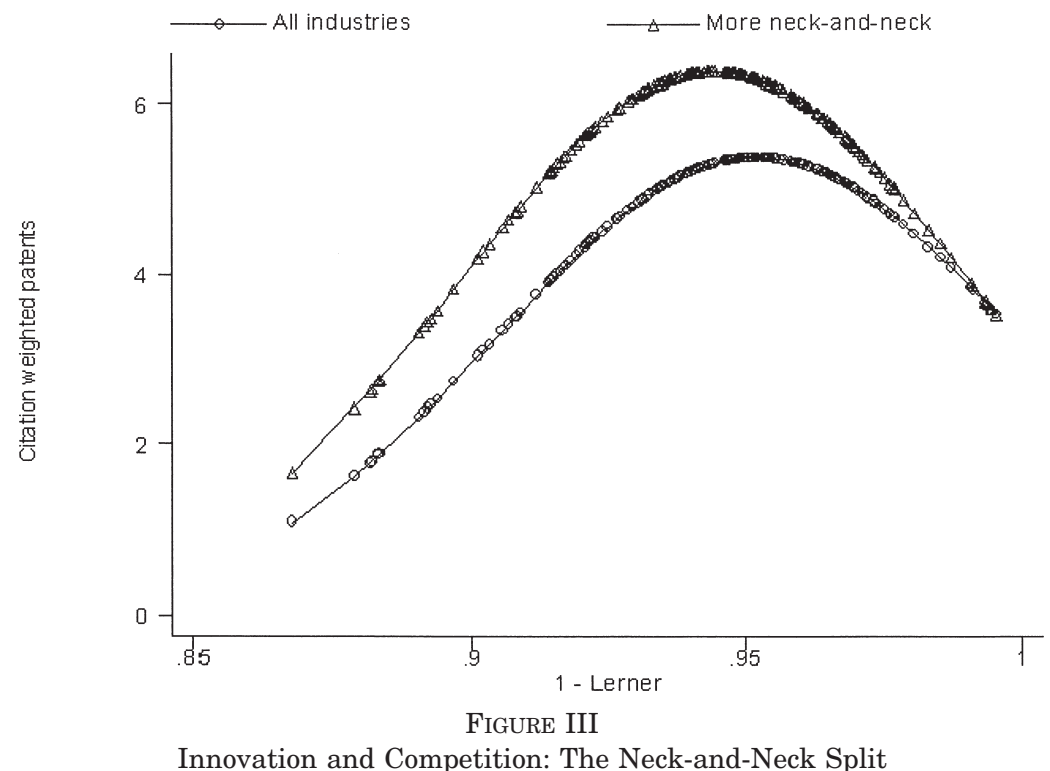

The figure plots a measure of competition on the $x$-axis against citationweighted patents on the $y$-axis. Each point represents an industry-year. The circles show the exponential quadratic curve that is reported in column (2) of Table I. The triangles show the exponential quadratic curve estimated only on neck-and-neck industries that is reported in column (4) of Table III.

\section{CONCLUSIONS}

This paper investigates the relationship between product market competition (PMC) and innovation using a flexible nonlinear estimator. We find evidence that the competitioninnovation relationship takes the form of an inverted-U shape, with industries distributed across both the increasing and decreasing sections of the U-shape. This inverted-U is robust to a number of alternative specifications, including identifying the causal impact of competition by exploiting a series of major policy reforms in the United Kingdom.

To understand what is driving this inverted-U shape, we extend the current theoretical literature on step-by-step innovation to produce a model that delivers an inverted-U prediction. In this model competition may increase the incremental profit from innovating, labeled the "escape-competition effect," but competition may also reduce innovation incentives for laggards, labeled the "Schumpeterian effect." The balance between these two ef- 
fects changes between low and high levels of competition, generating an inverted-U relationship. In addition, this extension of the theory provides two new predictions. First, the equilibrium degree of technological neck-and-neckness among firms should decrease with PMC, and second, the higher the average degree of neck-and-neckness in an industry, the steeper the inverted-U relationship between PMC and innovation. We take these two additional predictions to the data and find them to be consistent with the data. This dual empirical and theoretical approach provides useful results on the impact of competition and closeness in technology space on innovation, and also a model to understand this and experiment with potential policy reforms.

\section{Appendix 1: Proofs}

\section{Proof of Proposition 1}

To solve for the equilibrium research intensities $n_{0}$ and $n_{-1}$ of neck-and-neck and laggard firms, we use Bellman equations. More precisely, let $V_{m}$ (respectively, $V_{-m}$ ) denote the steady state value of being currently a leader (respectively, a follower) in an industry with technology gap $m$, and let $r$ denote the rate of time discount. We have the following Bellman equations:

$$
\begin{gathered}
r V_{1}=\pi_{1}+\left(n_{-1}+h\right)\left(V_{0}-V_{1}\right) ; \\
r V_{-1}=\pi_{-1}+\left(n_{-1}+h\right)\left(V_{0}-V_{-1}\right)-\left(n_{-1}\right)^{2} / 2 ; \\
r V_{0}=\pi_{0}+\overline{n_{0}}\left(V_{1}-V_{0}\right)+n_{0}\left(V_{-1}-V_{0}\right)-\left(n_{0}\right)^{2} / 2 .
\end{gathered}
$$

In words, the annuity value $r V_{1}$ of currently being a technological leader in an industry with gap $m=1$ at date $t$ equals the current profit flow $\pi_{1}$, minus the expected capital loss $\left(n_{-1}+\right.$ $h)\left(V_{0}-V_{1}\right)$ from having the follower catch up by one step with the leader. The annuity value $r V_{-1}$ of currently being a laggard, is equal to the current profit flow $\pi_{-1}$ plus the expected capital gain $\left(n_{-1}+h\right)\left(V_{0}-V_{-1}\right)$ from catching up with the leader minus the R\&D cost ${ }^{22}\left(n_{-1}\right)^{2} / 2$. Finally, in the Bellman equation for a neck-and-neck firm, there is no help factor $h$ because there is no leader, and $\overline{n_{0}}$ denotes the $R \& D$ intensity by the other firm

22. It follows by the same argument as used in Aghion et al. [2001] that the equilibrium real wage rate will equal unity given our choice to normalize expenditures equal to unity. 
in the same sector; in a symmetric Nash equilibrium both firms' $R \& D$ intensities are equal; that is,

$$
\overline{n_{0}}=n_{0} .
$$

Now, using the fact that each firm chooses its own R\&D intensity to maximize its current value, that is, to maximize the right-hand side of the corresponding Bellman equation, we obtain the first-order conditions:

$$
\begin{gathered}
n_{-1}=V_{0}-V_{-1} ; \\
n_{0}=V_{1}-V_{0} .
\end{gathered}
$$

Eliminating the $V$ 's between the Bellman equations and first-order conditions (13) to (17), yield the reduced form $R \& D$ equations:

$$
\begin{gathered}
\frac{\left(n_{0}\right)^{2}}{2}+(r+h) n_{0}-\left(\pi_{1}-\pi_{0}\right)=0 \\
\frac{\left(n_{-1}\right)^{2}}{2}+\left(r+h+n_{0}\right) n_{-1}-\pi_{0}-\frac{\left(n_{0}\right)^{2}}{2}=0 .
\end{gathered}
$$

This system is recursive, as the first equation solves for $n_{0}$, and then given $n_{0}$ the second equation solves for $n_{-1}$. For the special case where $r=0$, we use the relationship $\pi_{0}=(1-\Delta) \pi_{1}$ to obtain

$$
\begin{gathered}
n_{0}=-h+\sqrt{h^{2}+2 \Delta \pi_{1}} \\
n_{-1}=-\left(h+n_{0}\right)+\sqrt{h^{2}+n_{0}^{2}+2 \pi_{1}} .
\end{gathered}
$$

We immediately see that $n_{0}$ increases, whereas $n_{-1}$ decreases with higher product market competition. ${ }^{23}$ This establishes Proposition 1.

Proof of Proposition 2

Let

$$
x=n_{0} .
$$

23. From equation (20),

$$
\frac{\partial n_{0}}{\partial \Delta}=\frac{\pi_{1}}{n_{0}+h}>0 .
$$

From this and equation (21),

$$
\frac{\partial n_{-1}}{\partial \Delta}=\frac{\partial n_{0}}{\partial \Delta}\left[-1+\frac{n_{0}}{n_{-1}+h+n_{0}}\right]<0 .
$$


According to equation (21) above,

$$
n_{-1}=\sqrt{x^{2}+B}-x-h,
$$

where

$$
B=h^{2}+2 \pi_{1} .
$$

Thus, we can reexpress the aggregate innovation rate (10) as

$$
v(x)=4 x \frac{\sqrt{x^{2}+B}-x}{\sqrt{x^{2}+B}+x},
$$

with

$$
\nu^{\prime}(x)=4 B\left(\frac{1}{\sqrt{x^{2}+B}+x}\right)^{2}\left(1-\frac{2 x}{\sqrt{x^{2}+B}}\right) .
$$

The expression

$$
f(x)=1-\frac{2 x}{\sqrt{x^{2}+B}}
$$

is decreasing in $x$, with a unique value:

$$
\tilde{x}=\sqrt{B / 3},
$$

at which $f(x)=0$. Therefore, $v(x)$ is quasi-concave, with $v^{\prime}(x) \gtreqless$ 0 as $x \lesseqgtr \tilde{x}$. Therefore, the inverted-U pattern will obtain whenever $\tilde{x} \in(\underline{x}, \bar{x})$, the escape-competition effect will dominate if $\bar{x} \leq$ $\tilde{x}$ and the Schumpeterian effect will always dominate if $\underline{x} \geq \tilde{x}$.

Now let $\eta=h / \sqrt{\pi_{1}}$. One can easily establish that

$$
\frac{\bar{x}}{\tilde{x}}=\frac{\sqrt{\eta^{2}+2}-\eta}{\sqrt{\left(\eta^{2}+2\right) / 3}} \quad \text { and } \quad \frac{x}{\tilde{x}}=\frac{\sqrt{\eta^{2}+1}-\eta}{\sqrt{\left(\eta^{2}+2\right) / 3}} .
$$

Thus, the inverted-U pattern will obtain whenever

$$
\sqrt{\eta^{2}+1}<\sqrt{\left(\eta^{2}+2\right) / 3}+\eta<\sqrt{\eta^{2}+2} ;
$$

the escape-competition effect will strictly dominate over the whole interval $[\underline{x}, \bar{x}]$ whenever

$$
\sqrt{\left(\eta^{2}+2\right) / 3}+\eta \geq \sqrt{\eta^{2}+2} ;
$$

finally, the Schumpeterian effect will dominate over the whole interval $[\underline{x}, \bar{x}]$ whenever 


$$
\sqrt{\left(\eta^{2}+2\right) / 3}+\eta<\sqrt{\eta^{2}+1} .
$$

Each of the corresponding three regions is nonempty, which establishes Proposition 2.

Proof of Proposition 3

From equations (9) and (21) we have

$$
\mu_{1}=\frac{2 n_{0}}{\sqrt{n_{0}^{2}+B}+n_{0}},
$$

where $B$ is defined in the proof of Proposition 2 above. From this and (11):

$$
\begin{aligned}
\frac{\partial c}{\partial \Delta} & =2 \pi_{1}\left[\left(1-\mu_{1}\right)-\left(\frac{1}{4}-\varepsilon\right) \frac{\partial \mu_{1}}{\partial \Delta}\right] \\
& =2 \pi_{1}\left[\frac{\sqrt{n_{0}^{2}+B}-n_{0}}{\sqrt{n_{0}^{2}+B}+n_{0}}-\left(\frac{1}{4}-\varepsilon\right) \frac{\partial \mu_{1}}{\partial \Delta}\right] \\
& =2 \pi_{1}\left(\frac{\sqrt{n_{0}^{2}+B}-n_{0}}{\sqrt{n_{0}^{2}+B}+n_{0}}\right)\left[1-\left(\frac{1}{4}-\varepsilon\right)\left(\frac{2}{\sqrt{n_{0}^{2}+B}}\right) \frac{\partial n_{0}}{\partial \Delta}\right],
\end{aligned}
$$

where $\varepsilon=1-\Delta$. From this and Proposition 1 ,

$$
\frac{\partial c}{\partial \Delta}=2 \pi_{1}\left(\frac{\sqrt{n_{0}^{2}+B}-n_{0}}{\sqrt{n_{0}^{2}+B}+n_{0}}\right)\left[1-\left(\frac{1}{4}-\varepsilon\right)\left(\frac{2 \pi_{1}}{\sqrt{n_{0}^{2}+B}}\right) \frac{1}{n_{0}+h}\right],
$$

so we need only show that

$$
\left(\sqrt{n_{0}^{2}+B}\right)\left(n_{0}+h\right)>2\left(\frac{1}{4}-\varepsilon\right) \pi_{1} .
$$

This clearly holds when $\varepsilon \geq 1 / 4$. So suppose that $\varepsilon<1 / 4$. Then we need only show that

$$
\left(n_{0}^{2}+B\right)\left(n_{0}+h\right)^{2}>4\left(\frac{1}{4}-\varepsilon\right)^{2} \pi_{1}^{2} .
$$

It follows from equations (20) and (21) that

$$
\sqrt{n_{0}^{2}+B}=n_{-1}+n_{0}+h>n_{0}+h
$$

so

$$
\left(n_{0}^{2}+B\right)>\left(n_{0}+h\right)^{2}=h^{2}+2(1-\varepsilon) \pi_{1}>2(1-\varepsilon) \pi_{1} .
$$


Therefore,

$$
\left(n_{0}^{2}+B\right)\left(n_{0}+h\right)^{2}>4(1-\varepsilon)^{2} \pi_{1}^{2},
$$

which implies condition (22).

Proof of Proposition 4

Note that the expected technological gap is given by

$$
G=\mu_{0} \cdot 0+\mu_{1} \cdot 1=\mu_{1}=\frac{2 n_{0}}{2 n_{0}+n_{-1}+h},
$$

which can be reexpressed as

$$
G=\left[1+\frac{\sqrt{n_{0}^{2}+B}-n_{0}}{2 n_{0}}\right]^{-1} .
$$

This latter expression is clearly increasing in $n_{0}$ and therefore with product market competition. This establishes Proposition 4.

Remark. The expected technological gap

$$
G=\left[1+\frac{n_{-1}+h}{2 n_{0}}\right]^{-1}
$$

is decreasing in $h$. This stems from the fact that $n_{0}$ is decreasing in $h$ whereas $n_{-1}+h$ is increasing in $h$. To see the former, note that, from equation (20),

$$
\frac{\partial n_{0}}{\partial h}=-\frac{n_{0}}{n_{0}+h} \in(-1,0),
$$

whereas the latter follows from this and equation (21):

$$
\frac{\partial n_{-1}}{\partial h}=\frac{h}{\sqrt{h^{2}+n_{0}^{2}+2 \pi_{1}}}-1+\left(\frac{n_{0}}{\sqrt{h^{2}+n_{0}^{2}+2 \pi_{1}}}-1\right) \frac{\partial n_{0}}{\partial h}>-1,
$$

since

$$
n_{0}<\sqrt{h^{2}+n_{0}^{2}+2 \pi_{1}}
$$

and

$$
\frac{\partial n_{0}}{\partial h}<0
$$


Proof of Proposition 5

Since

$$
B=h^{2}+2 \pi_{1},
$$

therefore, $h$ will affect $\tilde{x}=\sqrt{B / 3}$ and $v(\tilde{x})$ via its positive effect on $B$. Assume that $\tilde{x}$ is interior to the interval $(\underline{x}, \bar{x})$. From the envelope theorem, the marginal effect of $B$ on

$$
v(\tilde{x})=\max _{x \in(\underline{x}, \bar{x})} v(x)
$$

is just equal to the direct effect

$$
E=\frac{\partial}{\partial B}\left\{x \frac{\sqrt{x^{2}+B}-x}{\sqrt{x^{2}+B}+x}\right\},
$$

which is unambiguously positive. The marginal effect of $h$ is $E$. $(\partial B / \partial h)$ which is therefore also positive. Therefore, more neckand-neck industries (those with larger $h$ ) have a higher peak in the inverted $\mathrm{U}$. Moreover, the peak occurs at the value of $\Delta$ such that $x=n_{0}=\sqrt{B / 3}$, or equivalently,

$$
0=-\sqrt{h^{2}+2 \Delta \pi_{1}}+h+\sqrt{\left(h^{2}+2 \pi_{1}\right) / 3} .
$$

The peak lies farther to the right on the $\Delta$ line in more neck-andneck industries if $d \Delta / d h<0$, where $\Delta$ is implicitly defined by (24). Applying the implicit functions theorem to (24), we get

$$
\frac{d \Delta}{d h}=\frac{\sqrt{h^{2}+2 \Delta \pi_{1}}}{\pi_{1}} \cdot F,
$$

where

$$
F=-\frac{h}{\sqrt{h^{2}+2 \Delta \pi_{1}}}+1+\frac{h / 3}{\sqrt{\left(h^{2}+2 \pi_{1}\right) / 3}}>0,
$$

since

$$
h<\sqrt{h^{2}+2 \Delta \pi_{1}} .
$$

Therefore, $d \Delta / d h>0$. This establishes Proposition 5 .

Appendix 2: Summary Statistics

Table IV presents the descriptive statistics on our unbalanced panel spanning 17 two-digit industries from 1973 to 1994. 
TABLE IV

Descriptive Statistics

\begin{tabular}{|c|c|c|c|c|}
\hline & $\begin{array}{l}\text { Mean } \\
\text { (s.d.) }\end{array}$ & Median & Min & Max \\
\hline Patents & $\begin{array}{c}6.59 \\
(8.52)\end{array}$ & 3.5 & 0 & 54 \\
\hline Cite weighted patents & $\begin{array}{c}6.65 \\
(8.43)\end{array}$ & 3.35 & 0 & 45 \\
\hline 1-Lerner & $\begin{array}{c}0.95 \\
(0.023)\end{array}$ & 0.95 & 0.87 & 0.99 \\
\hline Technology gap (m) & $\begin{array}{c}0.49 \\
(0.155)\end{array}$ & 0.51 & 0.080 & 0.81 \\
\hline
\end{tabular}

The sample is an unbalanced panel of 354 yearly observations on seventeen industries over the period 1973 to 1994.

This is taken from an underlying firm level panel of 311 firms which remain after matching the accounting and innovation data and cleaning the data (removing firms with missing observations, firms involved in major mergers, or firms with less than three years of consecutive data, see Bloom and Van Reenen [2002] for full details). The Lerner and technology gap measures are generated from the entire population of U. K. firms. From the data we can see even the industry level patenting count is highly skewed, with most industries taking out no patents in any given year. Patenting levels also vary strongly across industries, in part, due to different patenting intensities although in estimation the industry dummies will control for this. The Lerner averages 4 percent and ranges from 13 percent in Office and Computing Machinery in 1973 to less than 1 percent in Motor Vehicles in 1982.

HARVARD University AND Institute For Fiscal Studies

Centre for Economic Performance, London School of Economics

Institute for Fiscal Studies and University College London

Institute For Fiscal STUdies and University College London

BROWN UNIVERSITY

\section{REFERENCES}

Aghion, Philippe, Nick Bloom, Richard Blundell, Rachel Griffith, and Peter Howitt, "Competition and Innovation: An Inverted-U Relationship?" UCL Working Paper No. 04/06, July 2004.

Aghion, Philippe, Mathias Dewatripont, and Patrick Rey, "Competition, Financial Discipline, and Growth,” Review of Economic Studies, LXVI (1999), 825-852. 
Aghion, Philippe, Christopher Harris, and John Vickers, "Competition and Growth with Step-by-Step Innovation: An Example," European Economic Review, Papers and Proceedings, XLI (1997), 771-782.

Aghion, Philippe, Christopher Harris, Peter Howitt, and John Vickers, "Competition, Imitation and Growth with Step-by-Step Innovation," Review of Economic Studies, LXVIII (2001), 467-492.

Aghion, Philippe, and Peter Howitt, "A Model of Growth through Creative Destruction," Econometrica, LX (1992), 323-351.

$\mathrm{Ai}$, Chunrong, and Xiaohong Chen, "Efficient Estimation of Models with Conditional Moment Restrictions Containing Unknown Functions," Econometrica, LXXI (2003), 1795-1843.

Arrow, Kenneth, "Economic Welfare and the Allocation of Resources for Invention," in R. Nelson, ed., The Rate and Direction of Inventive Activity (Princeton, NJ: Princeton University Press, 1962), pp. 609-625.

Bloom, Nicholas, and John Van Reenen, "Patents, Real Options and Firm Performance," Economic Journal, CXII (2002), C97-C116.

Blundell, Richard, Rachel Griffith, and John Van Reenen, "Market Share, Market Value and Innovation in a Panel of British Manufacturing Firms," Review of Economic Studies, LXVI (1999), 529-554.

Blundell, Richard, and James Powell, "Endogeneity in Nonparametric and Semiparametric Regression Models," Chapter 8 in M. Dewatripont, L. P. Hansen, eds., Advances in Economics and Econometrics, Vol. II, Econometric Monograph Series 36 (Cambridge: Cambridge University Press, 2003).

Dixit, Avinash, and Joseph Stiglitz, "Monopolistic Competition and Optimum Product Diversity," American Economic Review, LXVII (1977), 297-308.

Geroski, Paul, Market Structure, Corporate Performance and Innovative Activity (Oxford, UK: Oxford University Press, 1995).

Gilbert, Richard, and David Newbery, "Preemptive Patenting and the Persistence of Monopoly," American Economic Review, LXXII (1982), 514-526.

Grossman, Gene, and Elhanan Helpman, Innovation and Growth in the Global Economy (Cambridge, MA: MIT Press, 1991).

Hall, Bronwyn, Adam Jaffe, and Manuel Trajtenberg, "Market Value and Patent Citations: A First Look," NBER working paper No. 7741, June 2000.

Hart, Oliver, "The Market Mechanism as an Incentive Scheme," Bell Journal of Economics, XIV (1983), 366-382.

Hausman, Jerry, Bronwyn Hall, and Zvi Griliches, "Econometric Models for Count Data and an Application to the Patents-R\&D Relationship," Econometrica, LII (1984), 909-938.

Martins, Joaquim Oliveira, Stephano Scarpetta, and Dirk Pilat, "Markup-up, Ratios in Manufacturing Industries: Estimates for 14 OECD Countries," OECD Working Paper No. 162, 1996.

Nickell, Steven, "Competition and Corporate Performance," Journal of Political Economy, CIV (1996), 724-746.

Reinganum, Jennifer, "Uncertain Innovation and the Persistence of Monopoly," American Economic Review, LXXIII (1983), 61-66.

Romer, Paul, "Endogenous Technological Change," Journal of Political Economy, XCVIII (1990), 71-102.

Salop, Steven, "The Noisy Monopolist: Imperfect Information, Price Dispersion, and Price Discrimination," Review of Economic Studies, XLIV (1977), 393-406.

Scharfstein, David, "Product Market Competition and Managerial Slack," RAND Journal of Economics, XIX (1988), 147-155.

Scherer, Fredrick, "Market Structure and the Employment of Scientists and Engineers," American Economic Review, LVII (1967), 524-531.

Schmidt, Klaus, "Managerial Incentives and Product Market Competition," Review of Economic Studies, LXIV (1997), 191-213.

Schumpeter, Joseph, Capitalism, Socialism and Democracy (London: Allen Unwin, 1943).

Sutton, John, Technology and Market Structure (Cambridge, MA: MIT Press, 1998). 